\title{
POLA PLAN MAHASISWA JURUSAN SEJARAH UNIVERSITAS NEGERI MALANG DALAM KPL (KAJIAN DAN PRAKTIK LAPANGAN) II BERBASIS LESSON STUDY DI KOTA MALANG
}

\author{
Alfia Hasanah ${ }^{1}$, Mashuri ${ }^{1}$, Indah Wahyu Puji Utami ${ }^{1}$
}

Diterima 6 April 2018, Dipublikasikan 31 Oktober 2018

CPenulis (2018)

\begin{abstract}
This research purpose is to explore how history initial teachers plan their lesson for lesson study during the KPL (internship) on 8 schools in Malang. 22 subjects were observed and interviewed by researchers during the research. This research found that there are two patterns of planning conducted by the history initial teachers during their internship for their lesson study. First, the lesson plans were made collaboratively. Second, the lesson plans were made individually.
\end{abstract}

\section{Keywords}

lesson study, initial history teacher, lesson plan

\section{PENDAHULUAN}

Kegiatan studi pembelajaran (lesson Study) atau jugyokenkyu dalam istilah Bahasa Jepang menurut para ahli pendidikan Jepang telah dimulai sejak 1890-an atau kurang lebih 100 tahun yang lalu. Studi pembelajaran (lesson study) merupakan sebuah gerakan pendidikan yang dilakukan para guru dimaksudkan untuk mengimplementasikan "pengajaran berpusat pada siswa". Ada sumber lain yang mengatakan bahwa studi pembelajaran (lesson study) yang dimulai di Jepang sejak abad ke-19 bertujuan untuk membantu guru-guru yang menggunakan pembelajaran individual untuk mengembangkan pembelajaran kelompok yang dikembangkan oleh negara-negara Barat (Syamsuri \& Ibrohim, 2008:1).

Pengembangan studi pembelajaran (lesson study) di Indonesia pertama kali di perkenalkan oleh para tenga ahli Japan International Cooperation Agency (JICA) dalam rangkaian kegiatan follow-up program dari Indonesian Mathematics and Science Teaching Education Project (IMSTEP) pada akhir tahun 2004. IMSTEP, merupakan program kerjasama teknis antara Pemerintah Indonesia, dalam hal ini Departemen Pendidikan Nasional, dengan Pemerintah Jepang melalui lembaga bantuan luar negeri JICA dalam upaya meningkatkan mutu pendidikan matematika dan sains (MIPA) dari sekolah dasar sampai perguruan tinggi. Program ini bekerja sama mulai dari Oktober 1998 sampai dengan September 2005. Mitra kerja sama dengan FPMIPA Universitas Pendidikan Indonesia (UPI), FMIPA Universitas Negeri Yogyakarta (UNY), dan FMIPA Universitas Negeri Malang (UM) (Syamsuri \& Ibrohim, 2008:5). Meskipun demikian sampai saat ini belum semua guru dan calon guru memahami lesson study yang baik.

1 Jurusan Sejarah, Fakultas Ilmu Sosial, Universitas Negeri Malang alfiahhasana@gmail.com 
Dalam pengenalan studi pembelajaran (lesson study) dan implementasinya di Indonesia oleh para ahli tenaga Jepang dalam program IMSTEP JICA di tiga Universitas (UPI, UNY dan UM) pada tahun 2004/2005 digunakan tahapan yang lebih sederhana. Tiga tahap utama studi pembelajaran (lesson study), yakni: perencanan (Plan), pelaksanaan (Do), dan melihat kembali atau refleksi (See) seperti yang terlihat pada gambar 1.

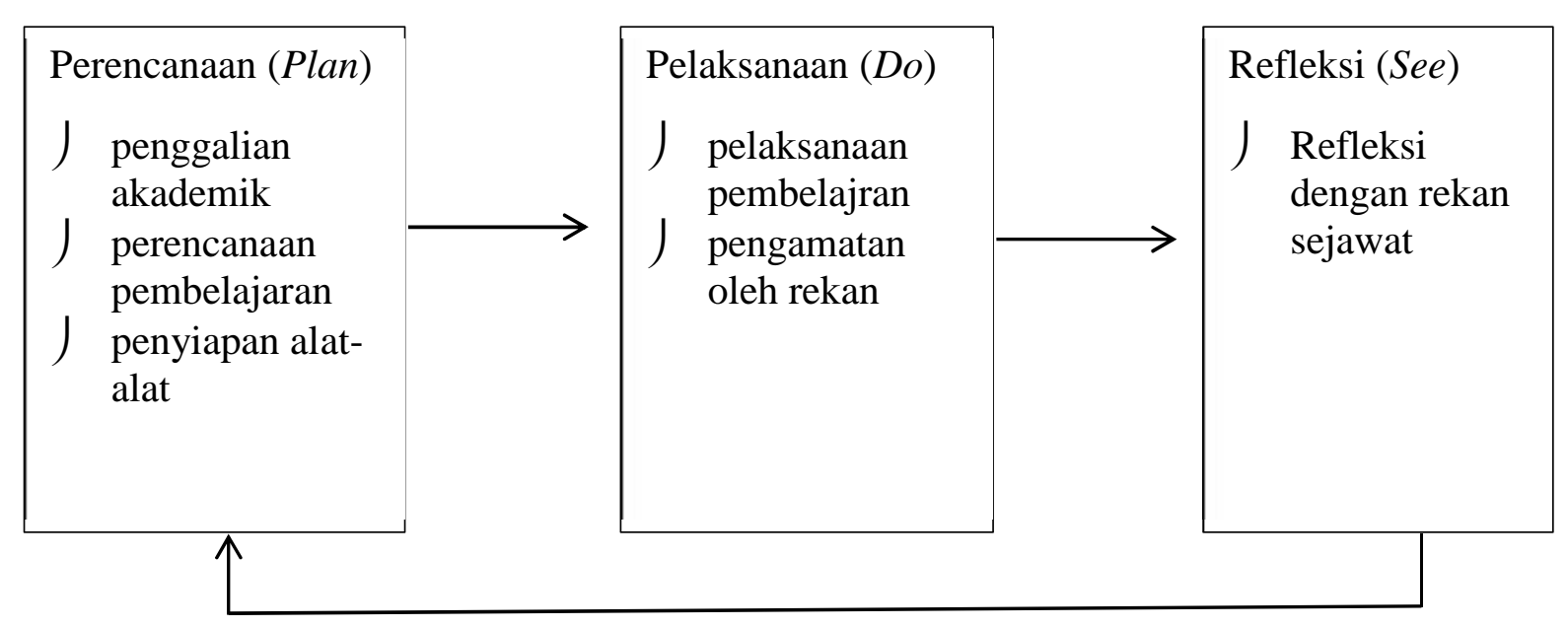

Gambar1 Daur studi pembelajaran yang terorientasi pada praktik Sumber: Syamsuri \& Ibrohim, 2008

Perkembangan lesson study di UM cukup baik. Di sini, lesson study diintegrasikan dengan kegiatan KPL (Kajian dan Praktik Lapangan). KPL adalah matakuliah yang memberikan wawasan dan pengalaman praktis kepada mahasiswa kependidikan dan non kependidikan tentang kegiatan riil di lapangan sehingga, mahasiswa memiliki kompetensi yang memadai dalam melaksanakan tugas sesuai dengan bidang keahliannya (Petunjuk Pelaksanaan Praktik Pengalaman Lapangan Keguruan Universitas Negeri Malang, 2015:2). Hakikat KPL (Kajian dan Praktik Lapangan) II adalah tahap lanjutan dari KPL I yang dilaksanakan di sekolah latihan untuk mengembangkan kompetensi mahasiswa dalam melaksanakan praktik pembelajaran secara riil dan utuh dalam kerangka lesson study.

Beberapa penelitian menujukkan bahwa lesson study dalam KPL ternyata memberikan banyak manfaat. Implementasi lesson study ternyata mampu meningkatkan motivasi siswa pada pembelajaran sejarah di Kota Malang (Yusrina, 2014). Lesson study dalam KPL juga terbukti mampu meningkatkan kolegialitas calon guru karena setiap mahasiswa yang terlibat dalam tim lesson study memiliki rasa memiliki dan mereka percaya bahwa keberhasilan kelompok sangat ditentukan oleh kekompakan anggota keolompok (Wahyuningtyas, Ratnawati, Adi, 2015). Kompetensi pedagogik calon guru juga meningkat dalam pelaksanaan lesson study pada KPL (Hidayat, Sumarmi, Amirudin, 2016). Namun, belum ada penelitian yang secara spesifik mengupas secara mendalam pelaksanaan tahapan-tahapan dalam lesson study pada KPL terutama plan atau perencanaan pembelajaran.

Tahapan lesson study yang pernah dikupas secara agak spesifik adalah tahap do (pelaksanaan). Penelitian Widiadi (2016) berfokus kepada peran pengamat atau observer dalam do (pelaksanaan) lesson study yang menemukan bahwa terdapat pola pengamatan observer lesson study bidang ilmu sosial dan humaniora, yaitu ada yang telah matang dan menjalakan tugas dan fungsinya dengan baik, serta sebaliknya. Temuan berupa pola dalam praktik lesson study sangat penting karena dapat digunakan untuk memperbaiki praktik di lapangan. 
Sementara itu pola plan dalam lesson study belum diteliti secara mendalam, padahal tahap ini sangat penting dalam lesson study. Dalam tahap plan, guru model bersama dengan tim atau kelompok merencanakan pembelajaran secara kolaboratif dimulai dari mengkaji kurikulum, hingga menyusun evaluasi pembelajaran (Syamsuri \& Ibrohim, 2008). Oleh karenanya, polapola plan dalam pelaksanaan lesson study, termasuk dalam KPL yang dilakukan oleh mahasiswa Jurusan Sejarah Universitas Negeri Malang (UM), penting untuk dikaji.

Mahasiswa Jurusan Sejarah UM pada umumnya telah mengenal mengenai lesson study sebelum pelaksanaan KPL. Para dosen di jurusan tersebut mempraktikkan lesson study untuk pengembangan profesionalitasnya (Utami \& Nafi'ah, 2016)). Selain itu mahasiswa juga mengenal lesson study dalam matakuliah Pengajaran Mikro yang wajib ditempuh sebelum KPL (Utami, Nafi'ah, \& Mashuri, 2016). Namun, pelaksanaan lesson study dalam KPL ternyata sangat beragam, termasuk dalam perencanaan atau plan. Penelitian ini bertujuan untuk mengeksplorasi dan menemukan pola perencanaan atau plan dalam lesson study yang dilakukan oleh mahasiswa Jurusan Sejarah UM dalam KPL II yang berlangsung di sekolah.

\section{METODE}

Penelitian ini merupakan penelitian kualitatif studi kasus. Penelitian melibatkan 22 orang mahasiswa Jurusan Sejarah angkatan 2014 yang melaksanakan KPL II pada Semester Gasal 2017/2018 di Kota Malang. Mereka telah mengenal dan menerapkan lesson study pada matakuliah Pengajaran Mikro dan KPL I yang berlangsung di kampus. Data dikumpulkan melalui observasi dan wawancara. Data yang terkumpul kemudian dianalisis dengan menggunakan teknik analisis interaktif Miles \& Huberman (2007) seperti yang ada pada gambar 2.



Gambar 2 Teknik analisis interaktif

Sumber: Miles \& Huberman (2007)

Tabel 1. Daftar Mahasiswa Jurusan Sejarah 2014 UM KPL Gemlombang II

\begin{tabular}{|c|c|}
\hline Lokasi Penelitian & Mahasiswa \\
\hline SMAN 7 Malang & $\begin{array}{l}\text { Arini Rhosidatin } \\
\text { Martyn Dirgantara } \\
\text { Rendi Arif Andrian }\end{array}$ \\
\hline SMKN 3 Malang & $\begin{array}{l}\text { Ayu Hardiyanti } \\
\text { Fransiskus Wahyu Pratama } \\
\text { Siti Ilmiyah }\end{array}$ \\
\hline SMKN 7 Malang & $\begin{array}{l}\text { Nur Cholidah } \\
\text { Putri Dwi Febriana } \\
\text { Rika Widhi Astari }\end{array}$ \\
\hline SMKN 8 Malang & Yahya Ilham Wahyudi \\
\hline SMKN 10 Malang & $\begin{array}{l}\text { Dedi Darmadi } \\
\text { Nindita Apriliana } \\
\text { Setia Nigrum }\end{array}$ \\
\hline
\end{tabular}




\begin{tabular}{cll}
\hline \multicolumn{1}{c}{ Lokasi Penelitian } & & Mahasiswa \\
\hline \multirow{2}{*}{ SMKN 11 Malang } & Afifah Nur Khumairoh \\
& $\begin{array}{l}\text { Mazidatun Ni'mah } \\
\text { Ummu Mahmudah }\end{array}$ \\
\hline \multirow{2}{*}{ SMKN 12 Malang } & Nurjiati \\
& Yuliarti Kurnia Pramai Sell \\
& Yuni Susanti \\
\hline \multirow{2}{*}{ SMK PGRI 2 Malang } & Dhita Nirwana Laraswati \\
& R. Hardiansyah E.P \\
& Rita Taismaniar \\
\hline
\end{tabular}

\section{HASIL DAN PEMBAHASAN}

Mahasiswa Jurusan Sejarah UM melaksanakan lesson study pada saat KPL II sebanyak dua kali. Dalam kedua kegiatan lesson study tersebut, tiap mahasiswa wajib melakukan plan atau perencanaan. Plan (perencanaan) dalam lesson study merupakan tahap awal di mana guru model secara kolaboratif melakukan pengkajian perencanaan pembelajaran, dimulai dari menentukan KI dan KD, materi hingga menyusun evaluasi pembelajaran (Syamsuri \& Ibrahim (2008).

Penelitian ini menunjukkan bahwa semua subyek penelitian merencanakan pembelajaran (plan). Meskipun demikian, praktik plan yang mereka lakukan sangat berbeda-beda. Terdapat dua pola plan yang dilakukan oleh mahasiswa Jurusan Sejarah dalam KPL II, yaitu melakukannya secara bersama-sama (kolaboratif) dan melakukannya sendiri (individual).

Tabel 2. Pelaksanaan Plan oleh Mahasiswa Jurusan Sejarah UM

\begin{tabular}{|c|c|c|c|}
\hline \multirow{2}{*}{ No } & \multirow{2}{*}{ Nama } & \multicolumn{2}{|c|}{ Plan } \\
\hline & & Bersama & Sendiri \\
\hline 1 & Afifah Nur Khumairoh & $\sqrt{ }$ & \\
\hline 2 & Arini Rhosidatin & $\sqrt{ }$ & \\
\hline 3 & Ayu Hardiyanti & $\sqrt{ }$ & \\
\hline 4 & Dedi Darmadi & $\sqrt{ }$ & \\
\hline 5 & Dhita Nirwana L & $\sqrt{ }$ & \\
\hline 6 & Fransiskus W.P.C & $\sqrt{ }$ & \\
\hline 7 & Hardiansyah & & $\sqrt{ }$ \\
\hline 8 & Martyn Dirgantara & & $\sqrt{ }$ \\
\hline 9 & Mazidatun Ni'mah & & $\sqrt{ }$ \\
\hline 10 & Nindita Arpiliana & $\sqrt{ }$ & \\
\hline 11 & Nur Cholidah & $\sqrt{ }$ & \\
\hline 12 & Nurjiati & $\sqrt{ }$ & \\
\hline 13 & Putri Dwi Febriana & $\sqrt{ }$ & \\
\hline 14 & Rendi Arif Andrian & $\sqrt{ }$ & \\
\hline 15 & Rika Widhi Astari & $\sqrt{ }$ & \\
\hline 16 & Rita Taismaniar & & $\sqrt{ }$ \\
\hline 17 & Setia Ningrum & $\sqrt{ }$ & \\
\hline 18 & Siti Ilmiah & $\sqrt{ }$ & \\
\hline 19 & Ummu Mahmudah & & $\sqrt{ }$ \\
\hline 20 & Yahya Ilham Wahyudi & $\sqrt{ }$ & \\
\hline 21 & Yuliarti Kurnia P.S & $\sqrt{ }$ & \\
\hline 22 & Yuni Susanti & & $\sqrt{ }$ \\
\hline & Total & 16 & 6 \\
\hline
\end{tabular}

Berdasarkan tabel 2, jumlah mahasiswa yang melakukan plan secara bersama atau kolaboratif lebih banyak dari yang melakukannya secara sendiri atau individual. Kegiatan yang dilakukan secara individu seperti merancang perangkat pembelajaran, membuat RPP, membuat media pembelajaran, menentukan model pembelajaran yang sesuai. Sementara itu, tahap plan (perencanaan) yang dilakukan secara bersama-sama membahas garis besar pembelajaran yang akan dilakukan, mendiskusikan media dan metode pembelajaran apa yang 
akan diterapkan, kemudian menentukan siapa saja observer yang akan terlibat, serta membuat nomer punggung.

Mahasiswa melakukan plan secara kolaboratif pada umumnya melakukannya dengan rekannya satu jurusan yang KPL II di tempat yang sama. Sebagai contoh, Fransiskus Wahyu Pratama C mengungkapkan bahwa ia melakukan plan "... bersama dengan teman-teman dari jurusan sejarah yakni Siti Ilmiah dan Ayu Hardiyanti serta beberapa teman dari jurusan lain" (wawancara, 7 Januari 2018). Ada pula yang melibatkan rekan satu jurusan, lain jurusan, bahkan melibatkan guru pamong dan dosen pembimbing. Arini Rhosidatin mengungkapkan bahwa "... saya melakukan tahap plan (perencanaan) secara bersama-sama, bersama teman KPL saya yakni Rendi, Martyin dan Pak Munir" (wawancara, 8 Desember 2017). Selain itu, Dedi Darmadi mengungkapkan bahwa “...pada tahap plan (perencanaan) saya lakukan dengan pihak-pihak yang terlibat dalam lesson study seperti guru, dosen pembimbing, dan para observer yang mengamati kegiatan pembelajaran di kelas" (wawancara, 20 Desember 2017).

Tabel 3. Pihak Yang Terlibat Dalam Plan Secara Kolaboratif

\begin{tabular}{|c|c|c|c|c|c|}
\hline \multirow[b]{2}{*}{ No } & \multirow[b]{2}{*}{ Nama } & \multicolumn{4}{|c|}{ Pihak yang terlibat dalam plan } \\
\hline & & $\begin{array}{l}\text { Teman satu } \\
\text { jurusan }\end{array}$ & $\begin{array}{c}\text { Teman lain } \\
\text { jurusan }\end{array}$ & Guru pamong & Dosen pembimbing \\
\hline 1 & Afifah Nur Khumairoh & $\sqrt{ }$ & $\sqrt{ }$ & & \\
\hline 2 & Arini Rhosidatin & $\sqrt{ }$ & & $\sqrt{ }$ & \\
\hline 3 & Ayu Hardiyanti & $\sqrt{ }$ & & & \\
\hline 4 & Dedi Darmadi & $\sqrt{ }$ & & $\sqrt{ }$ & $\sqrt{ }$ \\
\hline 5 & Dhita Nirwana L & $\sqrt{ }$ & & & \\
\hline 6 & Fransiskus W.P.C & $\sqrt{ }$ & $\sqrt{ }$ & & \\
\hline 7 & Nindita Arpiliana & $\sqrt{ }$ & & $\sqrt{ }$ & $\sqrt{ }$ \\
\hline 8 & Nur Cholidah & $\sqrt{ }$ & & & \\
\hline 9 & Nurjiati & & & $\sqrt{ }$ & \\
\hline 10 & Putri Dwi Febriana & $\sqrt{ }$ & & & \\
\hline 11 & Rendi Arif Andrian & $\sqrt{ }$ & & & \\
\hline 12 & Rika Widhi Astari & $\sqrt{ }$ & & & \\
\hline 13 & Setia Ningrum & $\sqrt{ }$ & & & \\
\hline 14 & Siti Ilmiah & $\sqrt{ }$ & & & \\
\hline 15 & Yahya Ilham Wahyudi & $\sqrt{ }$ & & & \\
\hline 16 & Yuliarti Kurnia P.S & $\sqrt{ }$ & & & \\
\hline & Jumlah & 15 & 2 & 4 & 2 \\
\hline
\end{tabular}

Proses plan secara bersama-sama ini sesuai dengan salah satu prinsip lesson study yaitu kolaborasi. Sato (2012) menyebutkan bahwa tahap plan merupakan proses di mana para guru saling membahas dan mendalami materi pelajarannya, saling mempelajari berbagai media atau alat peraga, serta cara menjalankan tahap inti. Dalam kegiatan plan, pihak-pihak yang terlibat dapat saling belajar satu sama lain untuk menyusun rencana pembelajaran yang dapat digunakan untuk membelajarkan siswa. Dengan demikian, kolaborasi yang dilakukan dalam tahap ini akan dapat mengarah pada pembentukan learning community.

Ada pula mahasiswa yang melaksanakan plan secara individu. Tabel 1 menunjukkan ada 6 mahasiswa yang membuat plan sendiri, yaitu Hardiansyah, Martyn Dirgantara, Mazidatun Ni'mah, Rita Taismaniar, Ummu Mahmudah, dan Yuni Susanti. Mereka memiliki alasan masing-masing untuk melakukan plan secara individual.

Yuni Susanti mengungkapkan bahwa "saya melakukannya sendiri karena lebih enak sendiri mengerjakannya lebih fokus" (wawancara, 25 Agustus 2017). Sedangkan Hardiansyah mengungkapkan bahwa "melakukan plan secara pribadi karena saya ingin mematangkan rencana yang ingin saya capai" (wawancara, 27 Desember 2017). Martyn Dirgantara mengungkapkan bahwa "saya melakukan sendiri karena rekan KPL satu jurusan tidak mau ribet" (wawancara, 6 Januari 2018). Mazidatun Ni'mah mengungkapkan bahwa "plan (perencanaan) dibuat sendiri-sendiri (individu) bukan bersama kelompok karena kelompok sibuk dengan plan (perencanaan) masing-masing jadi dalam kelompok buat sendiri-sendiri" (wawancara, 14 Desember 2017). Rita Taismaniar mengungkapkan bahwa "iya kalok 
perencanaan dalam kelas itu aku, tapi kalau aplikasinya aku minta bantuan sama Hardian dan Dita contoh menjadi observer" (wawancara, 8 Januari 2018). Ummu Mahmudah mengungkapkan bahwa "pada waktu KPL mahasiswa sudah sibuk sendiri dengan mengajarnya" (wawancara, 8 Januari 2018).

Tabel 3. Alasan Mahasiswa Jurusan Sejarah 2014 yang melakukan plan (perencanaan) Secara Individu

\begin{tabular}{cll}
\hline \multicolumn{1}{c}{ No } & \multicolumn{1}{c}{ Nama } & \multicolumn{1}{c}{ Alasan Plan Sendiri } \\
\hline 1 & Hardiansyah & ingin mematangkan rencana yang ingin dicapai \\
\hline 2 & Martyn Dirgantara & rekan KPL satu jurusan tidak mau ribet \\
\hline 3 & Mazidatun Ni'mah & teman satu kelompok sibuk dengan plan (perencanaan) masing-masing \\
\hline 4 & Rita Taismaniar & ingin sendiri \\
\hline 5 & Ummu Mahmudah & pada waktu KPL mahasiswa sudah sibuk sendiri dengan mengajarnya \\
\hline 6 & Yuni Susanti & lebih suka mengerjakannya sendiri agar lebih fokus \\
\hline
\end{tabular}

Berdasarkan data di atas dapat disimpulkan bahwa secara garis besar ada dua alasan mengapa mereka melakukan plan sendiri. Alasan pertama karena ingin fokus mencapai tujuan. Alasan kedua adalah karena rekan satu tim dalam KPL II sibuk dengan tugasnya masing-masing sehingga mereka melakukan plan sendiri. Namun, hal ini bertentangan dengan prinsip lesson study yang menekankan pada kolaborasi selama plan, do, dan see. Pada tahapan plan (perencanaan) seharusnya guru model secara kolaboratif dengan rekan satu tim melakukan pengkajian rencana pembelajaran yang dimulai dari mengkaji kurikulum, hingga menyusun evaluasi pembelajaran. Akan tetapi, ada pula mahasiswa Jurusan Sejarah yang juga melakukan plan (perencanaan) secara kolaboratif.

Mahasiswa yang melakukan plan sendiri ternyata mengalami berbagai hambatan. Hambatan yang mereka hadapi sebagian besar dalam hal memilih metode, model, dan strategi pembelajaran yang akan digunakan yang sesuai dengan kondisi kelas, dan masalah waktu yang kurang sehingga susah untuk berdiskusi. Kesulitan itu mereka hadapi karena mereka tidak memiliki teman atau rekan yang bisa diajak untuk saling berbagi dan diskusi. Hal ini sangat berbeda dengan mahasiswa yang melakukan plan secara kolaboratif. Pada umumnya mereka tidak memiliki masalah dalam merencanakan pembelajaran. Rekan yang terlibat dalam plan secara kolaboratif memberikan kontribusi positif terhadap perencanaan.

\section{SIMPULAN}

Mahasiswa Jurusan Sejarah UM melakukan kegiatan lesson study dalam KPL II. Salah satu kegiatan yang mereka lakukan dalam lesson study adalah plan atau perencanaan pembelajaran. Secara garis besar ada dua pola plan yang dilaksanakan pada saat KPL II, yaitu secara kolaboratif dan individual. Mahasiswa yang melakukan plan secara kolaboratif melibatkan rekan satu jurusan, guru pamong, dan dosen pembimbing. Mereka mendapatkan manfaat dari kolaborasi dalam plan. Sementara itu mereka yang melakukan plan secara individual cenderung mengalami hambatan. Mahasiswa yang melakukan plan secara individual beralasan karena ingin fokus dan rekan satu timnya sibuk dengan tugas masingmasing di KPL II sehingga tidak bisa plan secara bersama.

\section{DAFTAR PUSTAKA}

Hidayat, Nur Wahid, dkk. 2(016). Lesson Study Sebagai Model Pembinaan Profesi

Kependidikan Bagi Mahasiswa KPL S2 Pendidikan Geografi Universitas Negeri Malang. Dalam Inda Wayu Puji Utami (Ed.), Seminar Nasional: Praktik Lesson Study Ilmu Sosial Dan Humaniora (hlm.136-138). Malang: Fakultas Ilmu Sosial Universitas Negeri Malang.

Petunjuk Pelaksanaan Praktik Pengalaman Lapangan Keguruan Universitas Negeri Malang. (2015). Malang: Universitas Negeri Malang.

Sato, Masaki. (2012). Dialog dan Kolaborasi di Sekolah Menengah Pertama Praktik Learning Community. Jakarta: Pelita. 
Syamsuri, Istamar \& Ibrohim. (2008). Lesson Study: Model Pembinaan Pendidik Secara Kolaboratif Dan Berkelanjutan; Dipetik Dari Program SISTTEM-JICA di Kabupaten Pasuruan-Jawa Timur (2006-2008). Malang: Universitas Negeri Malang.

Utami, I. W., \& Nafi'ah, U. (2016). Developing Lecturer Collegiality Trough Lesson Study. 6th International Conference on Lesson Study (pp. 232-240). Singaraja: Asosiasi Lesson Study Indonesia (ALSI).

Utami, I. W., Nafi'ah, U., \& Mashuri. (2016). A Model of Microteaching Lesson Study Implementation on the Prospective History Teacher Education. Journal of Education and Practice.

Wahyuningtyas, Neni, dkk. (2015). Membangun Kolegialitas Calon Guru IPS Melalui Lesson Study. Jurnal Sejarah dan Budaya. (Online), 9 (2): 12, (http://www.journal.um.ac.id), diakses 22 Juli 2017.

Widiadi, Aditya N. (2016). Pola Pengamatan Observer Dalam Kegiatan Lesson Study Bidang Ilmu Sosial Dan Humaniora. Malang: Universitas Negeri Malang. (Online), (www.um.ac.id). Diakses 30 November 2016. 